\section{A EDUCAÇÃO DO CAMPO COMO UM DIREITO DOS SEUS SUJEITOS COLETIVOS E COMO UM DEVER DO ESTADO}

\section{THE EDUCATION OF THE FIELD AS A RIGHT OF ITS COLLECTIVE SUBJECTS AND AS A DUTY OF THE STATE}

Maryângela Ribeiro de Aquino Lira Lopes ${ }^{1}$

\section{RESUMO}

O objetivo deste artigo é apresentar a educação do campo como um direito a ser respeitado e garantido e como um dever Constitucional do Estado, por meio de políticas públicas específicas à realidade do campo, principalmente no contexto político atual de instabilidade e retrocessos. Para isso, o texto estrutura-se em três partes: a primeira apresenta a contextualização histórica da educação do campo, estabelecendo um paralelo entre a educação rural, que contempla os interesses da elite burguesa, representada no campo pelo agronegócio e o latifúndio e a educação do campo, que se volta aos camponeses e camponesas, no sentido de conscientizá-los e emancipá-los para a construção de uma nova sociedade; a segunda parte releva o papel e importância dos movimentos sociais para a implementação da educação do campo e seu fortalecimento, destaca, também, algumas conquistas legais já consolidadas; a terceira e última parte trata da situação da conjuntura política atual em face da crise capitalista, e dos desafios postos no sentido de garantir os direitos já conquistados e fazer cumprir os deveres do Estado, somente possível através dos movimentos sociais do campo, enfrentando o antagonismo de classe e a consequente correlação de forças, que se dá na luta diária de resistência e enfrentamento, na perspectiva de rompimento do atual sistema e construção de uma nova sociedade. Para tanto, valeu-se de teóricos que tratam das questões apontadas, tais como Arroyo (2011), Azevedo (2007), Caldart (2005), Fernandes (2002;2005), Paludo (2012); Molina (2005) entre outros. Utilizou-se, como procedimento metodológico a pesquisa bibliográfica. Ressalte-se que o trabalho, ora apresentado, tem a sua importância no sentido de destacar a educação do campo como um direito e dever do Estado e como um dos instrumentos de resistência e enfrentamento ao projeto neoliberal e de afirmação do projeto contra hegemônico de uma nova sociedade.
Palavras Chave: Educação do Campo; Direito e Dever Constitucional; Movimentos Sociais.

\section{ABSTRACT}

The purpose of this article is to present the education of the countryside as a right to be respected and guaranteed and as a constitutional duty of the State, through public policies specific to the reality of the field, especially in the current political context of instability and setbacks. For this, the text is structured in three parts: the first presents the historical contextualization of rural education, establishing a parallel between rural education, which contemplates the interests of the bourgeois elite, represented in the field by agribusiness and latifundio and education of the countryside, which turns to peasants and peasants, in the sense of raising awareness and emancipating them for the construction of a new society; the second part highlights the role and importance of social movements for the implementation of rural education and its strengthening, also highlights some legal achievements already consolidated; the third and final part deals with the situation of the current political conjuncture in the face of the capitalist crisis and the challenges posed to guarantee the rights already won and to enforce the duties of the State, only possible through the social movements of the countryside, facing antagonism of class and the consequent correlation of forces, which occurs in the daily struggle of resistance and confrontation, in the perspective of breaking the current system and building a new society. In order to do so, he used theorists who deal with the issues mentioned, such as Arroyo (2011), Azevedo (2007), Caldart (2005), Fernandes (2002; Molina (2005) among others. Bibliographic research was used as a methodological procedure. It should be emphasized that the work presented here has its importance in highlighting the education of the countryside as a right and duty of the State and as one of the instruments of resistance and confrontation with the neoliberal project and of affirmation of the counter-hegemonic project of a new society.

Keywords: Field Education; Right and Constitutional Duty; Social movements.

Submetido em: 28 de mar. 2019

Aceito em: 06 de mai. 2019

${ }^{1}$ Departamento de Tecnologia e Ciências Sociais - DTCS - Campus III, Universidade do Estado da Bahia, Juazeiro, Bahia - Brasil

E-mail para correspondência: maryangelaaquino@hotmail.com

Rev. ComCiência - jun. 2019, vol. 4, no. 4, p. 57-63 / doi: 10.36112/issn2595-1890.v4i1.p57-63 


\section{INTRODUÇÃO}

Defender a educação do campo nos dias de hoje como um direito dos povos do campo e como um dever constitucional do Estado é muito importante, pois, em face da crise do sistema capitalista e, do consequente acirramento das disputas entre projetos diferentes de sociedade, esse direito incorporado e consolidado, servirá de instrumento eficaz aos movimentos sociais e as classes trabalhadoras, para a edificação de um novo projeto de sociedade, de desenvolvimento e de ser humano.

Assim, objetivou-se, por intermédio desta pesquisa, apresentar a educação do campo, edificada na luta permanente dos movimentos sociais e pautada em princípios emancipadores e revolucionários, como um direito a ser respeitado e garantido e como um dever Constitucional do Estado, por meio de políticas públicas específicas à realidade do campo, principalmente no contexto político atual de instabilidade e retrocessos.

O modelo de desenvolvimento e de educação implantado no campo foi tão excludente que marca até hoje a ação das elites brasileiras. A origem de grande parte desse sistema desigual e excludente está relacionada com a forma de ocupação do território, onde foram priorizados projetos de grandes propriedades, voltadas para a monocultura de exportação.

O campo sempre foi visto e tratado pelas classes hegemônicas como um lugar de "atraso", "subdesenvolvido", um lugar de onde se deve extrair o máximo de benefícios para servir à cidade e ao capital. Um lugar onde a educação a ser implementada tenha por escopo qualificar os trabalhadores rurais para melhor servirem de mão de obra barata aos proprietários dos meios de produção.

Segundo Leite (2002):

A Educação Rural no Brasil, por motivos sócio-culturais, sempre foi relegada a planos inferiores, e teve por retaguarda ideológica o elitismo acentuado do processo educacional aqui instalado pelos jesuítas e a interpretação política ideológica da oligarquia agrária, conhecida popularmente na expressão: "gente da roça não carece de estudos. Isto é coisa de gente da cidade" (LEITE, 2002, p. 14).

Ao se contextualizar historicamente a educação voltada ao campo não se pode olvidar de considerar o processo de colonização, o regime de escravidão, o latifúndio e a predominância da produção extrativista e agrícola voltada para a exportação. Esta formação social não irá demandar a qualificação da força de trabalho, ocasionando um descaso total com o aprendizado escolar das camadas populares. A educação Rural cumpriu este papel, ao longo de muitos anos.

Não obstante, a partir das lutas desenvolvidas no campo pelos movimentos sociais rurais através de principais frentes: as Ligas Camponesas, entre as décadas de 1940 e 1960, e o Movimento dos Trabalhadores Rurais Sem Terra (MST), criado na década de 1980, bandeiras de luta como: reforma agrária, a justa distribuição da terra, da renda e das riquezas, a defesa dos valores humanistas e socialistas nas relações sociais, a demarcação e titulação das terras indígenas, quilombolas, de "fundo de parto", a soberania alimentar, a luta pela consolidação de uma educação do campo, estão sendo fortalecidas e servem de contraponto ao modelo de desenvolvimento capitalista.
Ao tratar sobre a educação do campo Kolling, Nery e Molina (1999), assim se manifestaram:

\begin{abstract}
A luta desse movimento busca conceber a educação básica do campo, voltada ao interesse do campo, voltada ao interesse e ao desenvolvimento sociocultural e econômico dos povos que habitam e trabalham no campo, atendendo às suas diferenças históricas e culturais para que vivam com dignidade e para que, organizados, resistam contra a exploração e a expropriação, ou seja, este do campo tem o sentido do pluralismo das idéias e das concepções pedagógicas: diz respeito à identidade dos grupos formadores da sociedade brasileira (conforme os artigos 206 e 216 da nossa Constituição) ( KOLLING; NERY; MOLINA 1999, p. 28-29).
\end{abstract}

Optou-se, assim, em desenvolver este trabalho abordando, inicialmente, um pouco da história de surgimento da educação do campo, estabelecendo um paralelo entre esta e a educação rural. Em seguida, destacouse a importância dos movimentos sociais para a implementação da educação do campo e seu fortalecimento, fazendo-se também uma referência a algumas conquistas legais já consolidadas, buscou-se ainda tratar da situação da conjuntura política atual, em face da crise capitalista, e dos desafios postos no sentido de garantir os direitos já conquistados e fazer cumprir os deveres do Estado e, por fim, suscitaram-se algumas reflexões conclusivas.

\section{CONTEXTO HISTÓRICO DA EDU- CAÇÃO DO CAMPO}

Ao longo da história do Brasil, o modelo de educação praticado no campo pelos diferentes governos constituiu-se num modelo tecnocrata urbano voltado a uma elite rural e com o escopo principal de formar uma mão- 
de-obra para atender ao mercado industrial.

Segundo Mészaros (2005), a educação institucionalizada no modo de produção capitalista, especialmente nos últimos 150 anos, esteve centrada nos propósitos de fornecer conhecimentos e pessoal necessários à máquina do capital em favor da expansão do sistema capitalista e ainda gerar e produzir um quadro de valores morais que validam os interesses dominantes, por meio da internalização ou da "dominação estrutural" implacavelmente imposta. Neste mesmo sentido, Vaz e Souza (2009) destacam que as instâncias política e econômica, como o Estado e o capitalismo, para atenderem aos intentos de lucro na produção, fornecem um ensino voltado a uma formação técnica.

O Estado, como instância política, e o capitalismo, como instância econômica, visavam o lucro da produção, proporcionando um ensino voltado a uma formação mais técnica, em que o trabalhador aprenderia o suficiente para desempenhar funções com o objetivo de fortalecer a ambos: os alunos usufruindo do processo escolar para atender seus objetivos, e o Estado pensando a educação que o trabalhador rural deveria ter (VAZ e SOUZA, 2009, p. 866).

Assim, as políticas educacionais se organizavam em conformidade com os interesses capitalistas. Para tanto, o ensino do campo e as escolas não tinham identidades. A escola rural era apenas um lugar para se aprender a ler, escrever e a "contar". Ressalte-se que a leitura e a escrita reproduziam a realidade da classe burguesa dominante, não havendo qualquer referência à história de vida e sacrifício dos trabalhadores rurais.

O geógrafo Bernardo Mançano Fernandes (1999), ao tratar sobre os componentes ideológicos da consciência urbana sobre o rural, escreveu:

O caipira preguiçoso (porque doente) metamorfoseia-se no rico fazendeiro cercado de múltiplas comodidades urbanas (como televisão de circuito fechado, meio de comunicação que não existia no Brasil quando a história foi escrita), graças à intervenção de dois agentes urbanos: o médico e os remédios de laboratório. Essa história, que expressa limpidamente os componentes ideológicos fundamentais da consciência urbana recente sobre o mundo rural, denuncia os vínculos reais entre o rural e o urbano. (FERNANDES, Bernardo Mançano, 1999, p.58).

Predominou, neste contexto, a chamada Educação Rural que, para alguns pensadores (FERNANDES, 2002; 2005; SCHWENDLER, 2004; CALDART, 2005; 2008; MOLINA, 2005; GHEDINI, 2007, entre outros), possui princípios e diretrizes que se articulam com a lógica mercadológica de produção do agronegócio, negando a existência de um campo de vida, culturas e saberes. A Educação Rural estava "adequada aos modelos políticos de desenvolvimento econômico efetivados no campo, cujas bases se fundamentavam nos interesses das classes dominantes" (AZEVEDO, 2007, p. 145).

Molina e Fernandes (2004) destacam que:

Os tímidos programas que ocorreram no Brasil para a educação rural foram pensados e elaborados sem seus sujeitos, sem sua participação, mas prontos para eles. (...). A educação rural projeta um território alienado porque propõe para os grupos sociais que vivem do trabalho da terra, um modelo de desenvolvimento que os expropria. (MOLINA; FERNANDES, 2004, p. 61-62).

Pode-se afirmar que a escolari- po teve sempre por escopo a superação da condição de marginalidade e incapacidade em que os mesmo se encontravam para a classe dominante. Nessas bases se assenta a justificativa do ensino de conteúdos instrumentais, uma vez que serviria apenas para lidar com o trabalho, também concebido como meramente instrumental. Além de não dispor de uma educação contextualizada e preocupada com o campo e com as questões do campo, "os programas e projetos desenvolvidos ao longo de décadas na perspectiva da educação rural sempre tiveram como premissa o atraso do sujeito do campo, o qual precisava ser educado para se enquadrar no sistema produtivo moderno" (FREITAS, 2011, p. 36).

Desse modo, a educação não respeitava a identidade dos camponeses, tornando-os meros receptores dos ensinamentos alienantes e vazios. A educação assim concebida nunca seria um meio de superação da condição subalterna em que vivam.

$\mathrm{O}$ que se encontrou, ao longo dos anos, nas escolas situadas no meio rural, segundo Arroyo (2012) foi a presença hegemônica de pedagogias de desenraizamento e desterritorialização, que buscavam enquadrar os modos de vida dos povos do campo a uma ideia de civilidade urbanocêntrica, inviabilizando todas as formas de conhecimento que não se encaixem nessa validade de forma legítima de conhecer. (ARROYO, 2012).

\section{A ATUAÇÃO E O PAPEL DOS MOVIMENTOS SOCIAIS PARA A EDUCAÇÃO DO CAMPO}

Os movimentos sociais sempre se constituíram em elementos de grande importância na história das conquistas sociais no Brasil. Surgido da iniciativa popular, motivados, na maioria

zação oferecida para os povos do cam- 
das vezes, pelas mazelas decorrentes da divergência entre o universo do capital em detrimento do trabalho, e, assim, do trabalhador, os mesmos têm representado a luta de resistência e posicionamento político da sociedade. Muitos hoje servem como exemplo: movimentos em defesa da natureza, das etnias, à orientação sexual, os movimentos pela terra e pelo teto, os quais se configuram em manifestos de ordem particular.

Movimentos sociais são fenômenos históricos, decorrentes de lutas sociais. Colocam atores específicos sob as luzes da ribalta em períodos determinados. Com as mudanças estruturais e conjunturais da sociedade civil e política, eles se transformam (GOHN, 2007, p.19-20).

Para Ghon (2008, p. 335), os movimentos sociais são ações sociais coletivas de caráter sociopolítico e cultural que viabilizam formas distintas de a população se organizar e expressar suas demandas.

É de extrema importância, principalmente na atualidade, o papel e a importância dos movimentos sociais, para a superação das desigualdades e de todas formas de dominação capitalista e para a construção de uma nova sociedade.

E no campo, os movimentos sociais que aí atuam envolvem o campesinato. Têm como principais bandeiras de luta a reforma agrária, a melhoria das condições de trabalho e o combate ao processo de substituição do homem pela máquina no meio agropecuário. Apesar de haver as mais variadas siglas, os movimentos sociais do campo constituíram-se, historicamente, a partir de duas principais frentes: as Ligas Camponesas, entre as décadas de 1940 e 1960, e o Movimento dos Trabalhadores Rurais Sem Terra (MST), criado na década de 1980 .
Neste sentido, contrapondo-se ao modelo de educação alienante e opressora, no contexto da luta pela terra, os movimentos sociais de base popular passam a questionar as políticas públicas educacionais praticadas pelo Estado na concepção da Educação Rural, propondo um rompimento com essa concepção, fazendo surgir a concepção da Educação do Campo.

Assim, como fruto das lutas políticas e do acirramento das contradições, abrem-se espaços para novos conceitos e significados. Segundo Molina e Fernandes (2004), o paradigma da Educação do Campo nasceu da luta pela terra e pela Reforma Agrária. A luta por educação do campo se originou no seio e no processo de construção do Movimento dos Trabalhadores Rurais Sem-Terra-MST.

De acordo com Paolli e Telles (2000), isso significa que:

Ao se fazerem reconhecer como
sujeitos capazes de interlocução
pública, a presença desses atores
coletivos na cena política teve o
efeito de desestabilizar ou mesmo
subverter hierarquias simbólicas
que os fixavam em lugares subal-
ternizados por entre uma trama
densa de discriminações e exclu-
sões, ao impor critérios igualitários
de reconhecimento e princípios
democráticos de legitimidade.
(PAOLLI e TELLES, 2000, p.
106).

A Educação do Campo, diferente do modelo neoliberal de educação, contribui com a construção de uma memória coletiva, do resgate da identidade do homem do campo por meio da educação junto às crianças, jovens e adultos, criando o sentimento de pertença ao grupo social ao qual a educação do campo está inserida, seja nas escolas dos assentamentos, acampamentos ou nas escolas em distritos, glebas, patrimônios, seringais ou comunidades quilombolas. Esta educação torna-se um direito conquistado por meio de lutas empreendidas pelos seus sujeitos, por isso, mais do que nunca, é um direito a ser respeitado.

Segundo Caldart, apud Lima Filho e Janata (2005):

A educação do campo é um projeto
educacional compreendido a partir
dos sujeitos que tenham o campo
como seu espaço de vida. Assim,
ela deve ser no e do campo. No
porque o povo tem o direito de ser
educado no lugar onde vive e do,
pois o povo tem o direito a uma
educação pensada desde o seu lugar
e com a sua participação vinculada
a sua cultura e as suas necessida-
des. (CALDART apud LIMA FI-
LHO e JANATA,2005, s/p).

Como fruto do processo de construção e implementação da educação do campo, forjado nas lutas sociais do campo, tanto por protagonistas os movimentos sociais, alguns avanços foram dados. Registra-se, inicialmente, a promulgação da Constituição Federal de 1988 que garante a educação como um direito de todos e dever do Estado, visando ao pleno desenvolvimento da pessoa, seu preparo para o exercício da cidadania e sua qualificação para o trabalho.( CF/88, art. 205). Adiante, passa a viger a Lei de Diretrizes e Bases da Educação Nacional n. ${ }^{\circ}$ 9.394/1996, cujos artigos 23, 24 e 28 reconhecem a diversidade do Campo e estabelecem orientações para o atendimento dessa realidade. Em 2001, como resposta aos movimentos populares, foram aprovadas as Diretrizes Operacionais da Educação do Campo que apontam: “O campo é mais que perímetro não urbano, é um campo de possibilidades que dinamizam a ligação dos seres humanos com a própria produção das condições de existência social e com as realizações da sociedade humana".

Ainda a Resolução $n^{\circ} 01$ que institui as Diretrizes Operacionais por 
uma Educação Básica nas Escolas do Campo de 03 de abril de 2002, do Governo Federal, dispõe, por meio do seu art. $2^{\circ}$, parágrafo único que:

A identidade da escola do campo é definida pela sua vinculação às questões inerentes à sua realidade, ancorando-se na temporalidade $\mathrm{e}$ saberes próprios dos estudantes, na memória coletiva que sinaliza futuros, na rede de ciência e tecnologia disponível da sociedade e nos movimentos sociais em defesa de projetos que associem as soluções exigidas por estas questões à qualidade social da vida coletiva no país.

Torna-se necessário registrar que, a partir do final da década de 1990, os Movimentos Sociais do Campo, tendo início pelo Movimento dos Trabalhadores Sem Terra - MST, têm conquistado espaço tanto nas agendas do governo, como no campo da legalidade, no sentido de consolidar uma educação voltada paro o campo. Uma educação que respeite os saberes, a cultura, os valores, as especificidades e as singularidades do povo do campo e do lugar onde vive. Uma educação que se vincula a um projeto social revolucionário de mudança para a construção de uma nova sociedade.

Muito embora, tenham ocorrido essas e outras conquistas para a consolidação da educação do campo, protagonizada pelos movimentos sociais, vive-se, na atualidade, um momento de intensa crise política e econômica, onde se registram recuos nas garantias de direitos sociais, o que pode fragilizar os movimentos populares e dificultar a mobilização e resistência dos trabalhadores do campo e da cidade.

A CONJUNTURA POLÍTICA ATUAL E OS DESAFIOS POSTOS AOS MOVIMENTOS SOCIAIS DO CAMPO.
Não se pode analisar a conjuntura política nacional na atualidade, sem proceder a uma análise em termos globais. A determinante principal da conjuntura econômica e política brasileira é a crise capitalista mundial.

Para Mézáros (2010), vive-se na era de uma crise histórica sem precedentes. Sua severidade pode ser medida pelo fato de que não se está frente a uma crise cíclica do capitalismo mais ou menos extensa, como as vividas no passado, mas a uma crise estrutural, profunda, do próprio sistema do capital. Como tal, esta crise afeta - pela primeira vez em toda a história - o conjunto da humanidade, exigindo, para esta sobreviver, algumas mudanças fundamentais na maneira pela qual o metabolismo social é controlado.

No entendimento do escritor francês Ladislau Dowbor (1981) a formação social capitalista está em crise, atingindo não só o grupo de países industrializados, mas o conjunto do sistema, englobando tanto os países capitalistas industrializados como o Terceiro Mundo. Aponta o autor como um dos fatores da crise a "polarização", ou seja, o desenvolvimento desigual, do mundo capitalista, que permitiu simultaneamente uma riqueza e uma pobreza de extensão desmedidas. De uma lado, a polarização Norte-Sul, do outro a polarização interna nos países subdesenvolvidos. Destaca Dowbor como efeito da modernização "extrovertida e dependente" que existente no Terceiro Mundo nos últimos trinta anos, a marginalização da maior parte das populações. Esta exclusão da imensa maioria das massas trabalhadoras do processo de modernização dá-se, segundo ele, através da interiorização da troca desigual entre setor moderno e o setor tradicional e também porque nem a tecnologia adotada, nem o perfil de produção permitem uma participação das massas no processo de mobilização para o desenvolvimento.

O grande capital internacional tenta sair da crise provocando uma queda histórica do valor da força de trabalho, com a massiva destruição de direitos, precarização dos empregos, demissão de funcionários públicos e cortes salariais. Da mesma forma o retrocesso econômico porque passa o Brasil aprofunda as perdas dos direitos dos trabalhadores, acirra as desigualdades sociais e expõe a face coercitiva do Estado na preservação dos interesses da burguesia brasileira associada ao capital financeiro internacional. Para sobreviver, o Estado capitalista brasileiro tem que se transformar cada vez mais em agente da espoliação do país pelo capital financeiro internacional.

O padrão de desenvolvimento capitalista, ao limitar a satisfação de consumo dos bens materiais a uma minoria detentora dos meios de produção, provoca grandes desigualdades sociais. O misto de realização e frustação inerentes ao sistema constituem numa crise civilizatória (SILVA, 2010).

Para uma nova estratégia de desenvolvimento defende Dowbor (1981) a necessidade da participação efetiva das massas camponesas.

\begin{abstract}
Torna-se necessário, em termos econômicos, de generalizar a tecnologia simples e acessível ao campo, e de criar as redes de serviços de apoio indispensáveis nas áreas de comercialização, estocagem, transportes e crédito, bem como orientar a industrialização, hoje concentrada em escoar e transformar os produtos do campo, para a produção de insumos agrícolas indispensáveis ao seu desenvolvimento. (DOWBOR, 1981, p.05).
\end{abstract}

Para o defensor da "teoria da resistência", Maclaren (2011), o grande desafio dos educadores críticos hoje estaria em lutar pela não integração da 
esfera pública nas práticas neoliberais e imperialistas do Estado e do capitalismo globalizado.

Estou mais interessado, nesse momento, em como a educação pode desempenhar um papel fundamental no desenvolvimento de novas formas de trabalho não-alienado por meio do desmantelamento das relações sociais capitalistas e do próprio capital. Estou tentando desenvolver formas de encorajar os estudantes a pensarem em tal possibilidade por meio da criação do que tenho chamado de "pedagogia revolucionária”. Por extensão, estou interessado no papel que a educação pode desempenhar numa sociedade mais ampla graças ao desmantelamento das leis de valor do capital como uma forma central de mediação entre seres humanos. (MCLAREN,2011, p.184).

Assim, em face da atual conjuntura política brasileira e mundial, especialmente na área rural onde ainda se predomina os interesses da elite agrária brasileira, os movimentos sociais do campo são desafiados a se manterem cada vez mais organizados e coesos na luta pela implementação de um projeto popular de desenvolvimento do campo, e de país, contrários á lógica do capital, com base em outras relações de produção. Impõe-se, também, aos movimentos sociais a permanente inclusão na pauta de lutas a garantia de uma educação do campo, que, resistindo à homogeneização cultural, traduza as diferenças, suas culturas e identidades, seu fazer próprio. Caldart (2002, p. 22) vai afirmar que nele há um projeto de educação próprio que, dentre outros fatores, tem por objetivo na "ação educativa ajudar no desenvolvimento mais pleno do ser humano, na sua humanização e inserção crítica na dinâmica da sociedade de que faz parte".

Arroyo(2004) destaca que:
O movimento social no campo representa uma nova consciência de direitos, à terra, ao trabalho, à igualdade, ao conhecimento, à cultura, à saúde e à educação. $\mathrm{O}$ conjunto de lutas e ações que os homens e mulheres do campo realizam, os riscos que assumem, mostram o quanto se reconhecem sujeitos de direitos (ARROYO, 2004, p.22).

\section{CONSIDERAÇÕES FINAIS}

Em face das discussões estabelecidas ao longo do texto, destaca-se a relevância do debate de educação do campo, como um direito conquistado na luta de homens e mulheres trabalhadores e que, principalmente por ser tão legítimo, deve ser absolutamente respeitado. Da mesma forma, em face das conquistas legais que asseguram a educação contextualizada à realidade do campo, pode-se exigir do Estado, como um dever, a oferta dessa educação como política pública permanente, com recursos próprios no orçamento da União.

A conquista do direito à educação no Movimento, de acordo com Caldart, ocorreu como resultado de muita luta. Os primeiros "[...] a se mobilizar foram as mães e professores, depois os pais e algumas lideranças do movimento" (2000, p. 145). Atualmente, o movimento pela educação no campo foi engrossado com a participação de universidades e por setores burocráticos do Estado.

A educação que emancipa deverá ser um grande instrumento de transformação da realidade excludente e desigual existente. As lutas do campo pela reforma agrária, pelos direitos de cidadania à população rural, pela legalização da terra e recursos para produção, pelos direitos previdenciários, pela saúde pública de qualidade, na luta contra o agronegócio, contra o trabalho escravo e outras formas de subordinação no campo, na luta pela demarcação e titulação de todas as terras indígenas e de comunidades remanescentes de quilombos, comunidades tradicionais, a luta pela afirmação identitária dos sujeitos aliam-se à luta por uma educação "do campo" que expressa uma nova concepção quanto ao campo, o camponês ou o trabalhador rural, fortalecendo o caráter de classe nas lutas em torno da educação.

Assim, entende-se que para enfrentar os desafios postos na construção e consolidação da educação do campo, como um direito dos seus sujeitos coletivos e como um dever do Estado, somente será possível através do fortalecimento dos movimentos sociais do campo, enfrentando o antagonismo de classe e a, consequente, correlação de forças, que se dá na luta diária de resistência e enfrentamento, na perspectiva de rompimento do atual sistema e construção de uma nova sociedade.

\section{REFERÊNCIAS}

ARROYO, Miguel Gonzalez e FERNANDES, Bernardo Mançano. A educação básica e o movimento social do campo - por uma educação básica do campo. Brasília: MST - Coordenação da Articulação Nacional Por uma Educação Básica do Campo, 2011. Disponível em: http://www.cedes.unicamp.br. Acesso em: 08 de junho de 2015.

ARROYO, Miguel Gonzalez. Políticas de formação de educadores (as) de campo. Cad. Cedes, Campinas, vol. 27, n. 72, p. 157-176, maio/ago., 2007. Disponível em: http://www.cedes.unicamp.br. Acesso em: 08 de maio. 2015.

BARDIN, L. Análise de Conteúdo. Lisboa. Edições 70, 2010.

BRASIL. Ministério da Educação e Cultura. Diretrizes operacionais para a 
educação básica nas escolas do campo. Resolução CNE/CEB N ${ }^{\circ}$ 1. Brasília: 2002. BRASIL. Ministério da Educação e Cultura. Lei de Diretrizes e Bases da Educação Nacional - Lei 9394/96. Brasília, 1996.

BRASIL. Ministério da Educação e Cultura. Referências para uma política nacional de educação do campo: cadernos de subsídios. Brasília, 2004a.

BRASIL. Constituição. (1988). Constituição da República Federativa do Brasil. Brasília: Senado, 1988. CALDART, Roseli Salete. Por uma Educação do Campo: traços de uma identidade em construção. In: KOLLING, Jorge Edgar; CERIOLI, Paulo Ricardo; CALDART, Roseli Salete. Educação do Campo: identidade e políticas públicas. Brasília: DF, 2002.

CALDART, Roseli Salete. A escola do campo em movimento. In: BENJAMIN, César; CALDART, Roseli Salete. Projeto popular e escolas do campo. Brasília, DF, 2000, nº 03.

CALDART, Roseli Salete (orgs.). Por uma educação do Campo. Brasília, DF: Articulação Nacional por Uma Educação do Campo, 2002. Coleção Por Uma Educação do Campo, n. ${ }^{\circ} 4$.

CALDART, Roseli Salete. A escola do campo em movimento. In: BENJAMIN, César; CALDART, Roseli Salete. Projeto popular e escolas do campo. Brasília, DF, 2000, nº 03.

CARVALHO, Jose Murilo de. A Cidadania no Brasil: o longo caminho. 10 ed. Rio de Janeiro: Civilização Brasileira, 2008.

CASTRO, Gilda. Professor submisso, aluno cliente: reflexões sobre a docência no Brasil. Rio de Janeiro: DP\&A, 2003.

D’AgOSTINE, Adriana. A educação do MST no contexto educacional brasileiro. 2009. 203 f. Tese (Doutorado em Educação) - Universidade Federal da Bahia, Salvador, 2009.

ESTEBAN, M. T. Diferenças, aprendizagem e avaliação: perspectiva póscolonial e escolarização. In: ESTE-
BAN, M. T.; AFONSO, A. J. (Org.). Olhares e Interfaces - reflexões críticas sobre avaliação. São Paulo: Cortez, 2010.

FERNANDES, Bernardo Mançano. Os campos da pesquisa em Educação do Campo: espaço e território como categorias essenciais. In: MOLINA, Mônica Castagna. Educação do Campo e Pesquisa: questões para reflexão. Brasília/MDA, 2006.

FREITAS, H. C. A. Rumos da Educação do Campo. Revista Em Aberto, Brasília, v. 24, n. 85, p. 35-49, abr. 2011.

MARTINS, Fernando José (Org.). Educação do campo e formação continuada de professores. Porto Alegre; Campo Mourão: EST Edições; FECILCAM, 2008.

MUNARIM, Antonio. Os campos da pesquisa em Educação do Campo: espaço e território como categorias essenciais. In: MOLINA, Mônica Castagna. Educação do Campo e pesquisa: questões para reflexão. Brasília/MDA, 2006. IV Colóquio Internacional Educação e Contemporaneidade ISSN 1982-3657 11

MÉSZAROS, István. A educação para além do capital. Trad. Isa Tavares. São Paulo: Boimtempo, 2005.

MST. Nossa história. Disponível em: www.mst.org.br/nossa-historia/. Acesso em: 21 maio 2011.

NASCIMENTO, Maria Isabel Moura. O Império e as primeiras tentativas de organização da educação nacional (1822-1889). Disponível em: . Acesso em: 30 maio 2011.

PINHEIRO, Maria do Socorro Dias. A concepção de educação do campo no cenário das políticas públicas da sociedade brasileira. Disponível em: . Acesso em: 30 maio 2011.

KOLLING, Edgar Jorge; NERY, Israel José; MOLINA, Mônica Castagna (Orgs.). A Educação Básica e o Movimento Social do Campo. Coleção Por Uma Educação Básica do Campo, $\mathrm{n}^{\circ}$ 1. Brasília: UnB, 1999.
LEITE, Sérgio Celani. Escola rural: urbanização e políticas educacionais. 2. ed. São Paulo: Cortez, 2002. 